\title{
Bone Mineral Density and the Risk of Incident Nonspinal Fractures in Black and White Women
}

\begin{abstract}
Jane A. Cauley, DrPH
Li-Yung Lui, MA, MS

Kristine E. Ensrud, MD, MPH

Joseph M. Zmuda, PhD

Katie L. Stone, PhD

Marc C. Hochberg, MD

Steven R. Cummings, MD

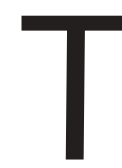

He ReCENTLY RELEASED US SURgeon general's report on bone health and osteoporosis noted that 1 in 2 individuals older than 50 years will be at risk for fractures from osteoporosis. ${ }^{1}$ Although fracture rates are lower among black women,$^{2}$ the report emphasizes that osteoporosis is a real risk for any aging man or woman. The identification of individuals at risk for osteoporotic fracture is essential for prevention. Low bone mineral density (BMD) has been shown to be an important predictor of increased fracture risk. ${ }^{3-6}$ However, these data are primarily based on studies of North American and European white women. Two case-control studies of fracture in black women reported a higher risk of fracture with low body mass index (BMI), low physical activity, and poor neuromuscular function, ${ }^{7,8}$ but neither of these studies measured BMD. Low heel, forearm, or finger BMD was associated with an increased 1-year risk of fracture in black women. ${ }^{9}$ It is not known whether BMD in the axial skeleton, which is the cri-
\end{abstract}

For editorial comment see p 2151.

Context Black women have a lower rate of fracture than white women, but whether bone mineral density (BMD) predicts fracture risk as well in black women as it does in white women is not established.

Objective To examine the association between BMD and incident nonspinal fractures in older black and white women.

Design, Setting, and Participants Prospective cohort study of baseline data collected from 1986 through 1990 (7334 white women aged 67-99 years) and from 1996 through 1998 (636 black women aged 65-94 years) at 4 US clinical centers in the Study of Osteoporotic Fractures; mean (SD) follow-up of 6.1 (1.5) years until October 1, 2004.

Main Outcome Measures Incident nonspinal fractures were confirmed by radiograpic report. Total hip and femoral neck BMD and bone mineral content were measured by dual energy $\mathrm{x}$-ray absorptiometry.

Results A total of 58 black women had a combined total of 61 fractures and 1606 white women had a combined total of 1712 fractures. In age-adjusted proportional hazard models, a 1-SD decrease in femoral neck BMD was associated with a 37\% increased risk of fracture in black women (relative risk [RR], 1.37; 95\% confidence interval $[\mathrm{CI}], 1.08$ $1.74)$ and a $49 \%$ increase in fracture in white women (RR, 1.49; $95 \% \mathrm{Cl}, 1.40-1.58)$. Adjustment for body weight and other risk factors for fracture weakened the association between $B M D$ and fracture, especially among black women (multivariable adjusted RR per 1-SD decrease in femoral neck BMD for black vs white women: $R R, 1.20[95 \% \mathrm{Cl}$, $0.93-1.55]$ vs $\mathrm{RR}, 1.42$ [95\% Cl, 1.32-1.52]). The absolute incidence of fracture across the pooled BMD distribution was $30 \%$ to $40 \%$ lower among black women at every BMD tertile. The lower risk of fracture among black compared with white women was independent of $\mathrm{BMD}$ and other risk factors ( $\mathrm{RR}, 0.48 ; 95 \% \mathrm{Cl}, 0.36-0.64)$.

Conclusions Decreased total hip and femoral neck BMD is associated with an increased risk of fracture in both older black and white women, but this relationship was largely explained by other risk factors in black women. Black women have a lower fracture risk than white women at every level of BMD. Race-specific normative databases may be appropriate for the densitometric definition of osteoporosis.

JAMA. 2005;293:2102-2108

www.jama.com

terion standard for assessing risk of osteoporosis, is related to fractures in older black women.

In the current study, we examined the relationship between BMD measured by dual-energy x-ray absorptiometry (DXA) and incident nonspinal fractures in 636 black and 7334 white women enrolled in the Study of Osteo-
Author Affiliations: Department of Epidemiology, University of Pittsburgh, Pittsburgh, Pa (Drs Cauley and Zmuda); Department of Medicine, Univeristy of California, San Francisco (Ms Lui and Dr Stone); VA Medical Center and Department of Medicine and Epidemiology, University of Minnesota, Minneapolis (Dr Ensrud); Departments of Medicine, Epidemiology, and Preventive Medicine, University of Maryland, Baltimore (Dr Hochberg); and California Pacific Medical Center, San Francisco (Dr Cummings).

Corresponding Author: Jane A. Cauley, DrPH, University of Pittsburgh, 130 DeSoto St, Crabtree Hall A543, Pittsburgh, PA 15261 (jcauley@pitt.edu). 
porotic Fractures (SOF). We tested 3 hypotheses: low BMD will predict fracture risk in black women; the magnitude of this association will be similar to that observed in white women; and the absolute risk of fracture in black and white women at a given BMD level will be similar.

\section{METHODS}

\section{Participants}

We enrolled 9704 white women into the SOF from 1986 to 1988 using population-based listings in Baltimore, $\mathrm{Md}$; Minneapolis, Minn; Portland, Ore; and the Monongahela Valley near Pittsburgh, $\mathrm{Pa}$. To be eligible to participate, women had to be aged 65 years or older and ambulatory. We excluded women who reported a bilateral hip replacement. Details of the cohort study have been published..$^{10}$ In the current study we analyzed 7334 white women who had a technically adequate hip BMD measurement at the second examination (1988-1990).

Black women were originally excluded from the SOF because of their low incidence of hip fractures. At a sixth SOF examination conducted between 1996 and 1998, we enrolled 662 black women aged 65 years or older. Race was self-declared and only women designating themselves as black were enrolled. Because the black women were recruited later in the SOF, we targeted black women aged 70 years or older. Of these, 636 women had technically adequate BMD measurements and follow-up information. Other inclusion and exclusion criteria were the same for both races. The protocol and consent forms were approved by the institutional review boards at all of the participating institutions. All women provided written informed consent.

\section{Bone Mineral Density}

Bone mineral content (BMC) was defined as the amount of bone mineral in grams in the region of interest. Bone mineral density was defined as the amount in grams of BMC divided by the region of interest in centimeters squared. The BMC and BMD of the total hip and the femoral neck were measured by DXA using Hologic QDR 1000 and 2000 scanners (Bedford, Mass). Details of the measurement and densitometry quality-control procedures have been published elsewhere. ${ }^{11,12}$ In brief, a random sample of scans was reviewed by technicians at a qualitycontrol center. In addition, all scans flagged by the technicians for certain problems (such as difficulty defining bone edges) were reviewed at the quality-control center. To assess longitudinal performance of the scanners, an anthropometric spine phantom was scanned daily and a hip phantom was scanned once per week at each clinic.

Areal BMD measurements are based on bone length and width. Because they do not include bone depth, the measurements only partially adjust for bone size. To test whether a volumetric measurement of BMD is a better predictor of fracture occurrence, we also calculated the femoral neck bone mineral apparent density (BMAD) using the formula ${ }^{13} \mathrm{BMC} / \mathrm{area}^{2}$ reported as $\mathrm{g} / \mathrm{cm}^{3}$.

\section{Other Measurements}

Body weight was measured using a balance beam scale and height was measured using the Harpenden stadiometer (Holtain Ltd, Crymych, United Kingdom). The BMI was calculated as the weight in kilograms divided by the square of height in meters. Participants were asked to stand up from a chair without using their arms and this was coded as able or unable. The participants also completed a questionnaire and interview that collected information on demographics, lifestyle (current smoking, alcohol use in the past 30 days), and medical and family history. Information was obtained on whether participants walked as a form of exercise. The number of blocks walked per day (assuming 12 blocks= $1.6 \mathrm{~km}$ ) as part of their normal routine and as part of an exercise routine was estimated. Kilocalorie expenditure from walking was calculated by assigning $8 \mathrm{kcal}$ per 1 block walked. ${ }^{14}$ Participants were asked to bring all prescription and over-the-counter medi- cations to the clinic for verification of use. Dietary calcium intake was estimated using the Block food frequency questionnaire $^{15}$ and expressed in milligrams per day.

\section{Fracture Ascertainment}

After the initial enrollment visit, all women were contacted by either letter or telephone every 4 months to ask if they had sustained a fracture; these contacts were 99\% complete. Women who reported a fracture were interviewed by telephone about the circumstances under which the fracture occurred. We excluded fractures that occurred because of a major trauma, eg, motor vehicle crash. Women could report having more than 1 fracture. The time to the first fracture was calculated as time from the baseline BMD measure to the event. All fractures were confirmed by radiographic report. We truncated the follow-up in the white women so that the average follow-up of 6.1 years would be the same in both racial groups.

\section{Statistical Analyses}

The characteristics of black and white women who had a fracture were compared with women who did not have a fracture using $t$ tests for continuous variables and $\chi^{2}$ tests for categorical variables. We used Cox proportional hazards models to estimate the relative risk (RR) of fracture and the 95\% confidence interval $(\mathrm{CI})$ for each SD decrease in BMC, BMD, or BMAD. The SD for each site was determined from the combined cohort of women. To compare the predictive value of various measurements, we analyzed the areas under receiver operating characteristic curves in the age-adjusted models. ${ }^{16,17} \mathrm{We}$ initially adjusted for age. Because of the major effect of body weight on BMD, ${ }^{18}$ we adjusted separately for age and body weight. In the full multivariable model, we adjusted for age, body weight, height, fracture since age 50 years, walking as a form of exercise, current calcium supplement use, current hormone use, alcohol consumption in the past 30 days, history of osteoarthritis or chronic obstructive pulmonary disease, falling 2 or 
more times in past year, using arms to stand up from a chair, and current smoking.

To compare the absolute rate of fracture at a given bone density level in black and white women, we calculated incidence rates of fracture per 1000 person-years across tertiles of $\mathrm{BMC}, \mathrm{BMD}$, and BMAD. The combined distribution of BMC, BMD, and BMAD in both black and white women were used to identify the cut points for the tertiles. To test whether BMD or BMAD and other risk factors account for the lower fracture rate among black women, we calculated the adjusted RR (95\% CI) of fracture among black com- pared with white women. $P<.05$ was considered significant. All analyses were performed using SAS version 8.2 (SAS Institute Inc, Cary, NC).

\section{RESULTS}

Black women were older, had a greater body weight and BMI, and were less likely than white women to report a fracture since age 50 years, a maternal history of fracture, walking for exercise, and current use of calcium supplements (TABLE 1). Dietary calcium intake was lower among black women. Use of thiazide diuretics and hormone therapy did not differ by race. Few black women reported bisphosphonate use. A greater

\begin{tabular}{|c|c|c|c|c|}
\hline & \multicolumn{2}{|c|}{ Black } & \multicolumn{2}{|c|}{ White } \\
\hline & $\begin{array}{c}\text { Fracture } \\
(n=58)\end{array}$ & $\begin{array}{c}\text { No Fracture } \\
(n=578)\end{array}$ & $\begin{array}{c}\text { Fracture } \\
(n=1606)\end{array}$ & $\begin{array}{c}\text { No Fracture } \\
(\mathrm{n}=5728)\end{array}$ \\
\hline Age, y & $76.2(5.6)$ & $75.3(5.0)$ & $74.4(5.5)$ & $73.1(4.9) \dagger$ \\
\hline Weight, kg & $71.5(16.3)$ & $76.6(15.9) \dagger$ & $65.1(12.6)$ & $66.9(12.4) \dagger$ \\
\hline Height, cm & $158.3(5.8)$ & $158.5(6.3)$ & $158.8(6.3)$ & $159.3(6.0) \dagger$ \\
\hline Body mass index $\neq$ & $28.5(6.3)$ & $30.5(6.1) \dagger$ & $25.8(4.6)$ & $26.4(4.6) \dagger$ \\
\hline \multicolumn{5}{|l|}{$\begin{array}{l}\text { Lifestyle } \\
\text { Walking }\end{array}$} \\
\hline Form of exercise, No. (\%) & $14(24.1)$ & $216(37.6) \dagger$ & $815(50.8)$ & $3013(52.6)$ \\
\hline Amount, kcal/wk§ & $635(1242)$ & $548(700)$ & $554(638)$ & $605(682) \dagger$ \\
\hline Consumed alcohol in past 30 d, No. (\%) & $12(20.7)$ & $164(28.4)$ & $1105(68.8)$ & $4107(71.7) \dagger$ \\
\hline Current smoking, No. (\%) & $5(8.6)$ & $46(8.0)$ & $128(8.0)$ & $439(7.7)$ \\
\hline Dietary calcium, mg/d & 665 (319) & $633(360)$ & $711(408)$ & $719(415)$ \\
\hline \multicolumn{5}{|l|}{ Current medication or supplement use, No. (\%) } \\
\hline Calcium & $13(23.2)$ & $163(28.8)$ & $648(41.2)$ & $1989(35.5) \dagger$ \\
\hline Hormone therapy & $9(16.4)$ & $90(16.2)$ & $170(10.8)$ & $892(15.9) \dagger$ \\
\hline Thiazide diuretics & $12(22.2)$ & $121(23.0)$ & $341(21.7)$ & $1182(21.1)$ \\
\hline Bisphosphonate & $2(3.5)$ & $10(1.8)$ & NA & NA \\
\hline \multicolumn{5}{|l|}{ Self-reported medical history, No. (\%) } \\
\hline Fracture since age 50 y & $16(27.6)$ & $118(20.8)$ & $852(53.1)$ & $2101(36.9) \dagger$ \\
\hline Maternal fracture history & $7(17.1)$ & $54(12.2)$ & $410(34.2)$ & $1338(30.5) \dagger$ \\
\hline Fair or poor health & $17(29.3)$ & $157(27.2)$ & $264(16.4)$ & $874(15.3)$ \\
\hline Osteoarthritis & $18(31.0)$ & $121(21.0) \dagger$ & $327(20.8)$ & 1065 (18.9) \\
\hline COPD & $10(17.2)$ & $78(13.5)$ & $162(10.2)$ & $484(8.6) \dagger$ \\
\hline Myocardial infarction & $5(8.6)$ & $64(11.1)$ & $100(7.3)$ & $338(7.0)$ \\
\hline Diabetes & $11(19.3)$ & $101(17.5)$ & $115(7.2)$ & $372(6.5)$ \\
\hline Hypertension & $39(67.2)$ & $364(63.1)$ & $630(39.3)$ & $2157(37.7)$ \\
\hline \multicolumn{5}{|l|}{ Fallen in past year } \\
\hline$\geq$ Once & $17(29.3)$ & $161(27.9)$ & $559(35.4)$ & $1631(29.1) \dagger$ \\
\hline$\geq$ Twice & $11(19.0)$ & $64(11.1) \dagger$ & $202(12.8)$ & $539(9.6) \dagger$ \\
\hline Use arms to stand up from a chair & $14(24.1)$ & $84(14.5) \dagger$ & $85(5.8)$ & $186(3.6) \dagger$ \\
\hline \multicolumn{5}{|c|}{$\begin{array}{l}\text { Abbreviations: COPD, chronic obstructive pulmonary disease; NA, not applicable because bisphosphonates were not } \\
\text { approved by the US Food and Drug Administration for marketing for osteoporosis from } 1986 \text { through } 1990 \text {. } \\
\text { *Values are expressed as mean (SD) unless otherwise indicated. Because of missing data, the denominator used to } \\
\text { calculate the percentages may vary. } \\
+P<.10 \text { for comparison of women who had a fracture with women who did not have a fracture. } \\
\text { †Calculated as weight in kilograms divided by the square of height in meters. } \\
\text { §Calculated by assigning } 8 \text { kcal per block walked. }\end{array}$} \\
\hline
\end{tabular}

proportion of white women reported consuming alcohol. Compared with white women, osteoarthritis, chronic obstructive pulmonary disease, diabetes, and hypertension were more common among black women. A similar proportion of both races reported a history of fall $(25.6 \%$ of black women and $28.9 \%$ of white women aged $65-69$ years, $26.4 \%$ and $30.8 \%$ for women aged $70-74$ years, $28.0 \%$ and $29.7 \%$ for women aged $75-79$ years, and $32.6 \%$ and $33.9 \%$ for women aged $\geq 80$ years, respectively). Compared with white women, a higher proportion of black women were not able to stand from a chair without using their arms.

As of October 1, 2004, after a mean (SD) follow-up of 6.1 (1.5) years, 58 black women had a combined total of 61 fractures and 1606 white women had a combined total of 1712 fractures. The specific fractures by site in black and white women, respectively, were hip or pelvis, 12 (19.7\%) and 347 (20.3\%); rib, $8(13.1 \%)$ and 141 (8.2\%); wrist, 7 $(11.5 \%)$ and 306 (17.9\%); finger or hand, $6(9.9 \%)$ and $90(5.3 \%)$; toes or feet, 11 (18\%) and 241 (14.1\%); arm, shoulder, or elbow, 5 (8.2\%) and 247 (14.4\%); leg, ankle, or knee, 12 (19.6\%) and 248 (14.5\%); and other, 0 and 92 (5.4\%). Compared with black women who did not have a fracture, black women who had a fracture were slightly older and had a lower body weight and BMI; were less likely to report walking as a form of exercise; and were more likely to report osteoarthritis, a history of falling 2 or more times in the past year, and use of arms to stand up from a chair (Table 1).

Compared with white women who did not have a fracture, white women who had a fracture were older; had a lower height, weight, and BMI; were more likely to report a past and maternal history of fracture; were more likely to report calcium supplement use, a history of chronic obstructive pulmonary disease, a history of falls in the past year, and use of arms to stand up from a chair; and were less likely to report hormone therapy use and alcohol consumption. 
Table 2. Bone Mineral Content, Bone Mineral Density, and Bone Mineral Apparent Density in Black and White Women by Fracture Status*

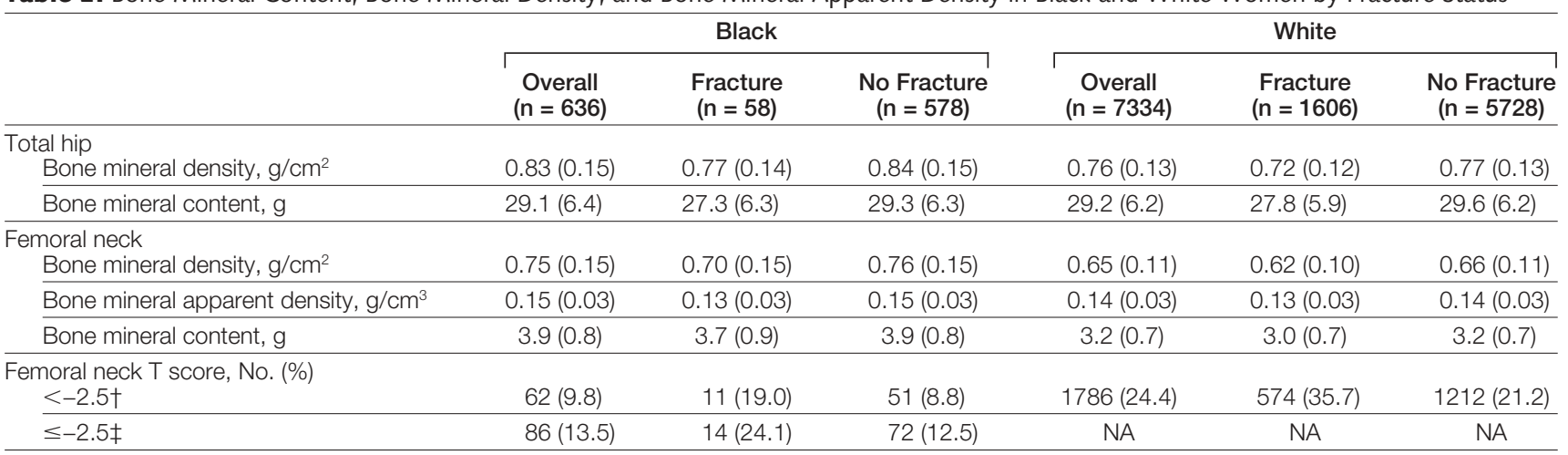

Abbreviation: NA, not applicable.

*Values expressed as mean (SD) unless otherwise indicated. All comparisons based on fracture status within racial groups are different at $P<.05$.

tWhite refer

White referent database used.

łBlack referent database used.

Compared with white women, black women had a $9 \%$ higher baseline total hip BMD, a 15\% higher femoral neck BMD, and a $17 \%$ higher femoral neck BMAD (TABLE 2). In both groups, BMD at the total hip and femoral neck was lower among women who had a fracture compared with women who did not have a fracture (Table 2). A higher percentage of both black and white women who had a fracture had a femoral neck $\mathrm{T}$ score of -2.5 or less. Use of a black referent database for the calculations of $\mathrm{T}$ scores resulted in a higher prevalence of black women with osteoporosis.

\section{Age-Adjusted Models}

In black and white women, respectively, after adjusting for age, the RR of fracture per 1-SD decrease in BMD was 1.44 (95\% CI, 1.12-1.86) and 1.47 (95\% CI, 1.39-1.56) for the total hip and 1.37 (95\% CI, 1.08-1.74) and 1.49 (95\% CI, 1.40-1.58) for the femoral neck (TABLE 3); all increases were statistically significant. Total hip and femoral neck BMC were related to the risk of nonspinal fractures, but the magnitude of the association was weaker. A $1-S D$ decrease in BMAD was associated with an RR of fracture of 1.59 (95\% CI, 1.16-2.18) and 1.34 (95\% CI, 1.261.43) in black and white women, respectively. For the areas under receiver operating characteristic curves, BMD in the total hip and femoral neck were better predictors of subsequent

Table 3. Relative Risk of Nonspinal Fracture in Black and White Women per 1-SD Decrease in $B M D, B M C$, or BMAD

\begin{tabular}{|c|c|c|c|c|}
\hline & \multicolumn{2}{|l|}{ Black } & \multicolumn{2}{|l|}{ White } \\
\hline & $\mathrm{RR}(95 \% \mathrm{Cl})$ & AUROC & $\mathrm{RR}(95 \% \mathrm{Cl})$ & AUROC \\
\hline \multicolumn{5}{|l|}{ Total hip } \\
\hline $\begin{array}{l}\text { BMD decrease of } 1 \text { SD }\left(0.134 \mathrm{~g} / \mathrm{cm}^{2}\right) \\
\text { Age adjusted }\end{array}$ & $1.44(1.12-1.86)$ & .63 & $1.47(1.39-1.56)$ & .63 \\
\hline Age and body weight adjusted & $1.34(1.01-1.78)$ & & $1.53(1.44-1.63)$ & \\
\hline Multivariable adjusted* & $1.23(0.92-1.65)$ & & $1.42(1.33-1.52)$ & \\
\hline \multicolumn{5}{|l|}{$\overline{B M C}$ decrease of $1 \mathrm{SD}(6.171 \mathrm{~g})$} \\
\hline Age adjusted & $1.34(1.01-1.79)$ & .59 & $1.29(1.22-1.36)$ & .60 \\
\hline Age and body weight adjusted & $1.18(0.85-1.64)$ & & $1.33(1.25-1.42)$ & \\
\hline Multivariable adjusted* & $1.10(0.80-1.51)$ & & $1.25(1.17-1.35)$ & \\
\hline \multicolumn{5}{|l|}{ Femoral neck } \\
\hline Age adjusted & $1.37(1.08-1.74)$ & .63 & $1.49(1.40-1.58)$ & .63 \\
\hline Age and body weight adjusted & $1.29(1.00-1.65)$ & & $1.52(1.42-1.63)$ & \\
\hline Multivariable adjusted* & $1.20(0.93-1.55)$ & & $1.42(1.32-1.52)$ & \\
\hline \multicolumn{5}{|l|}{ BMC decrease of $1 \mathrm{SD}(0.736 \mathrm{~g})$} \\
\hline Age adjusted & $1.28(0.98-1.66)$ & .60 & $1.29(1.22-1.36)$ & .60 \\
\hline Age and body weight adjusted & $1.16(0.88-1.53)$ & & $1.28(1.21-1.37)$ & \\
\hline Multivariable adjusted* & $1.10(0.83-1.44)$ & & $1.20(1.13-1.29)$ & \\
\hline \multicolumn{5}{|l|}{ BMAD decrease of $1 \mathrm{SD}\left(0.034 \mathrm{~g} / \mathrm{cm}^{3}\right)$} \\
\hline Age adjusted & $1.59(1.16-2.18)$ & .64 & $1.34(1.26-1.43)$ & .61 \\
\hline Age and body weight adjusted & $1.50(1.09-2.07)$ & & $1.32(1.24-1.40)$ & \\
\hline Multivariable adjusted* & $1.38(0.99-1.92)$ & & $1.28(1.20-1.37)$ & \\
\hline \multicolumn{5}{|c|}{$\begin{array}{l}\text { Abbreviations: AUROC, area under the receiver operating characteristic curve; BMAD, bone mineral apparent density; } \\
\text { BMC, bone mineral content; BMD, bone mineral density; Cl, confidence interval; RR, relative risk. } \\
\text { *Multivariable-adjusted model includes age, body weight, height, fracture since age } 50 \text { years, walking as form of ex- } \\
\text { ercise, current calcium supplement use, current hormone therapy use, alcohol consumption in the past } 30 \text { days, } \\
\text { diagnosis of osteoarthritis, diagnosis of chronic obstructive pulmonary disease, fallen } 2 \text { or more times in the past } \\
\text { vear. use arms to stand up from a chair, and current smoking. }\end{array}$} \\
\hline
\end{tabular}

fractures than were BMC measures $(P<.05)$ in black but not white women (Table 3).

\section{Multivariable-Adjusted Models}

Additional adjustment for body weight decreased the magnitude of the RR of fracture in black women (Table 3). The additional adjustment had little effect on the RR of fracture in white women. In the full multivariable model, a 1-SD decrease in total hip BMD was associated with a $42 \%$ increased risk of fracture in white 
Figure. Incidence Rate of Nonspinal Fracture Based on Tertiles of Bone Mineral Content, Bone Mineral Density, and Bone Mineral Apparent Density of the Femoral Neck in Black and White Women
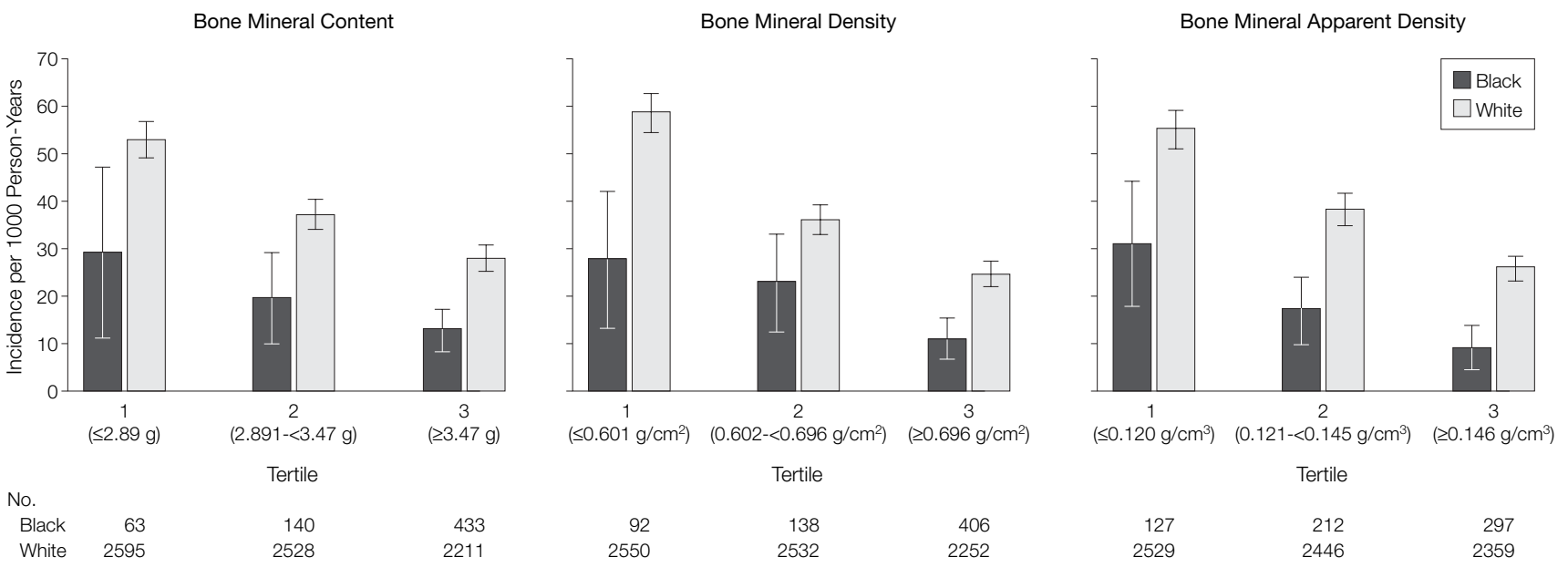

Error bars indicate $95 \%$ confidence intervals.

Table 4. Relative Risk of Fracture in Black Compared With White Women*

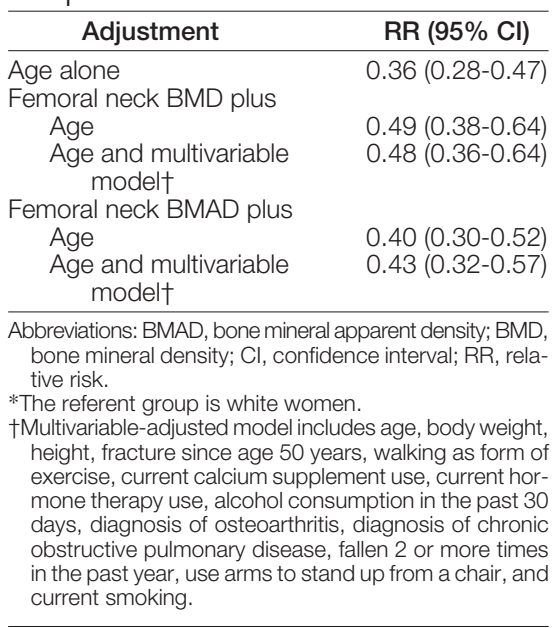

women independent of other covariates ( RR, $1.42 ; 95 \% \mathrm{CI}, 1.33$ 1.52). Among black women, the multivariable-adjusted RR of fracture per 1-SD decrease in total hip BMD was 1.23 (95\% CI, 0.92-1.65). Similar associations were found with femoral neck BMD. The BMC was not related to fracture occurrence in black women in the multivariable models. The association between volumetric BMAD and subsequent fracture was of borderline significance in black women.

\section{Absolute Incidence of Fracture} The incidence rate of nonspinal fracture by tertile of femoral neck BMC, BMD, and BMAD in black and white women is shown in the FIGURE. Within each racial group, fracture rates were highest among women with the lowest BMC, BMD, or BMAD. Nevertheless, within each tertile, fracture rates were $30 \%$ to $40 \%$ lower among black compared with white women. In ageadjusted models, black women had a $64 \%$ lower risk of fracture than white women (TABLE 4). Adjusting for BMD and other risk factors, the RR of fracture was 0.48 (95\% CI, 0.36-0.64) in black compared with white women.

\section{COMMENT}

We have demonstrated that reduced BMD of the hip and femoral neck is associated with an increased risk of all nonspinal fractures in older black women in age-adjusted models-a relationship largely mitigated by other risk factors. The strength of the association between BMD and all nonspinal fractures in black women after age adjustment appears to be similar to that observed for white women in the SOF ${ }^{19}$ and other cohorts. ${ }^{20}$ Total hip and femoral neck BMD were somewhat bet- ter predictors of fracture than $\mathrm{BMC}$, perhaps because BMC makes no correction for bone size. Among white women in the SOF, we also found that BMC was a poorer predictor of hip fracture than either BMD or BMAD. ${ }^{3}$

We hypothesized that if BMAD provides a more accurate estimate of volumetric BMD of the femoral neck, then it may be a stronger predictor of fracture than areal BMD alone. There was some suggestion that estimated femoral neck volumetric BMD had a stronger relationship to fractures than areal BMD for the prediction of fractures in black women, but the areas under receiver operating characteristic curves were not significantly different for BMD and BMAD, which is consistent with our observations in white women. ${ }^{21}$ Our results are also consistent with a recent study ${ }^{9}$ of peripheral BMD and fractures in a multiethnic cohort in which each 1-SD decrease in peripheral BMD T score was associated with a 1.54fold increased risk of fracture. However, the follow-up period was only 1 year. Moreover, the World Health Organization recommendations and the other guidelines for using BMD and interpreting BMD results for diagnosis are based on central DXA., ${ }^{1,22}$ 
An important implication of the improved life expectancy among black women $^{23}$ is that the overall impact of osteoporosis, a disease that is more prevalent among older individuals, will increase in blacks. About 24\% of the black women who had a fracture had a T score of -2.5 or less if a black referent database was used compared with $19 \%$ when a white referent database was used. However, despite the association between BMD and nonspinal fracture risk in black women, fracture incidence was 30\% to $40 \%$ lower among black women compared with white women at every BMD level. This was true for both areal BMD and estimated volumetric BMD of the femoral neck. The current clinical recommendation is to diagnose osteoporosis among nonwhites at or below a T score threshold of -2.5 using the uniform normative database for whites. ${ }^{24}$ Our results suggest that low BMD is useful to identify blacks at risk of experiencing an osteoporotic fracture and those who may benefit from therapy and other preventive measures. Our results also suggest that race-specific databases for black women may be appropriate.

The lower fracture rate among black women may reflect both skeletal and other factors. In models adjusting for $\mathrm{BMD}$ or BMAD, the differential fracture risk by race was attenuated somewhat; nevertheless, the lower RR of fracture among black women was independent of BMD and other covariates, suggesting that other factors account for their lower risk. Slower rates of bone loss ${ }^{25}$ among black women, possibly due to lower bone turnover, has been observed in some ${ }^{26}$ but not all studies $^{27}$ and could contribute to their lower rate of fracture. Microarchitectural and geometric differences may contribute. Calcaneal quantitative ultrasound measurements were higher ${ }^{28}$ and hip axis lengths were shorter in black ${ }^{29}$ compared with white women. Other factors could include lifestyle and anthropometric factors, although we adjusted for these covariates in our model. Differences in sex-steroid and growth hormones and metabolism also may con- tribute. Lower fall rates among black women have been reported in some studies, ${ }^{30}$ but we adjusted for falls in our analyses.

Osteoporosis and fracture occurrence appear to be strongly correlated with genetics. ${ }^{31}$ A maternal history of fracture confers a 2-fold increased risk of fracture that is independent of BMD. ${ }^{10}$ There has been rapid progress in identifying genes and alleles that determine BMD, but little progress in identifying genetic determinants of fracture, and in identifying genes that contribute to racial differences in fracture occurrence.

Among black women, the relationship between BMD and fracture was attenuated in the fully adjusted model. This was somewhat surprising because the overall variation in BMD explained by individual characteristics has been shown to be similar in blacks ${ }^{32}$ and whites. ${ }^{18}$ Nevertheless, these results suggest that lifestyle and medical and family history may be important determinants of BMD in black women and could account for the association between BMD and fracture.

The prospective design of our study avoids many of the potential biases inherent in case-control studies of BMD and fracture. We studied 2 wellcharacterized cohorts of communitydwelling black and white women. We used state-of-the-art measurements of BMD and controlled for a number of important covariates. However, our participants were likely to be healthier than average because they were volunteers and because we excluded women who were unable to walk without assistance.

Race was self-declared. Estimated European admixture among blacks ranges from $11.6 \%$ to $22.5 \%$ in the United States with considerably less in a Jamaican population (6.8\%). ${ }^{33}$ In our study, we had no information on admixture. Other factors that we did not measure include genetic and cultural factors. Future studies may consider assigning race based on the race and/or ethnicity of paternal and maternal grandparents, as well as measuring genetic and/or cultural factors.
Our estimated volumetric BMD may underestimate true volumetric BMD, but this is proportional in participants who had a fracture and controls and therefore would not alter our conclusions. ${ }^{34,35}$ The BMAD only partially adjusts for bone size; direct measures of volumetric BMD are needed to confirm our findings. Finally, we studied a smaller number of black women and our estimates of fracture incidence may be less precise.

In conclusion, decreased hip BMD is associated with an increased risk of fracture in older black women when adjusting for age but not other factors. The lower fracture rate in black compared with white women was independent of BMD and other risk factors. Our results suggest that race-specific normative databases may be appropriate for the densitometric definition of osteoporosis.

Author Contributions: Ms Lui had full access to all of the data in the study and takes responsibility for the integrity of the data and the accuracy of the data analysis.

Study concept and design: Cauley, Stone, Cummings. Acquisition of data: Cauley, Ensrud, Stone, Hochberg. Analysis and interpretation of data: Cauley, Lui, Ensrud, Zmuda, Stone, Hochberg.

Drafting of the manuscript: Cauley.

Critical revision of the manuscript for important intellectual content: Lui, Ensrud, Zmuda, Stone, Hochberg, Cummings.

Statistical analysis: Lui, Stone.

Obtained funding: Cauley, Ensrud, Stone, Hochberg, Cummings.

Administrative, technical, or material support: Cauley, Zmuda.

Study supervision: Stone, Cummings.

Financial Disclosures: Dr Cauley has received honoraria from Eli Lilly \& Co, Merck \& Co, and Novartis and has served on the speaker's bureau for Eli Lilly \& $\mathrm{Co}$ and Merck \& Co. No other authors reported financial disclosures.

Funding/Support: Supported in part by Public Health Service research grants AR35582, AR35583, AR35584, AR44811, and AG05407 from the National Institutes of Health.

Role of the Sponsors: The funding agencies had no direct role in the conduct of the study, the collection, management, statistical analyses, and interpretation of the data, preparation, or approval of the manuscript.

\section{REFERENCES}

1. US Department of Health and Human Services. Bone Health and Osteoporosis: A Report of the Surgeon General. Rockville, Md: US Dept of Health and Human Services; 2004.

2. Baron JA, Barrett J, Malenka D, et al. Racial differences in fracture risk. Epidemiology. 1994;5:42-47.

3. Cummings SR, Black DM, Nevitt MC, et al; Study of Osteoporotic Fractures Research Group. Bone density at various sites for prediction of hip fractures. Lancet. 1993;341:72-75.

4. Cummings SR, Black DM, Nevitt MC, et al; Study 
of Osteoporotic Fractures Research Group. Appendicular bone density and age predict hip fracture in women. JAMA. 1990;263:665-668.

5. Stone KL, Seeley DG, Lui LY, et al. BMD at multiple sites and risk of fracture of multiple types: longterm results from the Study of Osteoporotic Fractures. J Bone Miner Res. 2003;18:1947-1954.

6. Marshall $\mathrm{D}$, Johnell $\mathrm{O}$, Wedel H. Meta-analysis of how well measures of bone mineral density predict occurrence of osteoporotic fractures. BMJ. 1996;312: 1254-1259.

7. Grisso J, Kelsey J, Strom B, et al. Risk factors for hip fracture in black women. N Engl J Med. 1994;330: 1555-1559.

8. Bohannon A, Hanlon J, Landerman R, Gold D. Association of race and other potential risk factors with nonvertebral fractures in community-dwelling elderly women. Am J Epidemiol. 1999;149:1002-1009. 9. Barrett-Connor E, Siris ES, Wehren LE, et al. Osteoporosis and fracture risk in women of different ethnic groups. J Bone Miner Res. 2005;20:185-194 10. Cummings SR, Nevitt MC, Browner WS, et al; Study of Osteoporotic Fractures Research Group. Risk factors for hip fracture in white women. N Engl J Med. 1995;332:767-773

11. Ensrud KE, Palermo L, Black DM, et al. Hip and calcaneal bone loss increase with advancing age: Iongitudinal results from the Study of Osteoporotic Fractures. J Bone Miner Res. 1995;10:1778-1787.

12. Steiger $P$, Cummings $S R$, Black DM, Spencer $N E$, Genant HK. Age-related decrements in bone mineral density in women over 65. J Bone Miner Res. 1992; 7:625-632.

13. Katzman DK, Bachrach LK, Carter DR, Marcus R. Clinical and anthropometric correlates of bone mineral acquisition in healthy adolescent girls. J Clin Endocrinol Metab. 1991;73:1332-1339.

14. Paffenbarger RS Jr, Hyde RT, Wing AL, Hsieh CC. Physical activity, all-cause mortality, and longevity of college alumni. N Engl J Med. 1986;314:605-613.
15. Block G, Subar AF. Estimates of nutrient intake from a food frequency questionnaire: the $1987 \mathrm{Na}$ tional Health Interview Survey. J Am Diet Assoc. 1992; 92:969-977.

16. McNeil BJ, Hanley JA. Statistical approaches to the analysis of receiver operating characteristics curves. Med Decis Making. 1984;4:137-150.

17. Hanley J, McNeil BJ. A method of comparing the areas under receiving operating characteristic curve derived from small cases. Radiology. 1983;148:839-843. 18. Orwoll ES, Bauer DC, Vogt TM, Fox KM; Study of Osteoporotic Fractures Research Group. Axial bone mass in older women. Ann Intern Med. 1996;124:187196.

19. Black DM, Cummings SR, Genant HK, Nevitt MC, Palermo L, Browner W. Axial and appendicular bone density predict fractures in older women. J Bone Miner Res. 1992;7:633-638

20. Hui SL, Slemenda CW, Johnston CC Jr. Age and bone mass as predictors of fracture in a prospective study. J Clin Invest. 1988;81:1804-1809.

21. Cummings SR, Marcus $R$, Palermo L, et al; Study of Osteoporotic Fractures Research Group. Does estimating volumetric bone density of the femoral neck improve the prediction of hip fracture? a prospective study. J Bone Miner Res. 1994;9:1429-1432.

22. Cummings SR, Bates $D$, Black DM. Clinical use of bone densitometry: scientific review. JAMA. 2002;288: 1889-1897.

23. Arias E. United States life tables, 2001. Natl Vital Stat Rep. 2004;52:1-38.

24. Binkley NC, Schmeer P, Wasnich RD, Lenchik L. What are the criteria by which a densitometric diagnosis of osteoporosis can be made in males and non-Caucasians? J Clin Densitom. 2002;5(suppl):S19S27.

25. Cauley JA, Lui LY, Stone KL, et al. Longitudinal study of changes in hip bone mineral density among Caucasian and African-American Women. J Am Geriatr Soc. 2005;53:183-189.
26. Kleerekoper M, Nelson D, Peterson E, et al. Reference data for bone mass, calciotropic hormones and biochemical markers of bone remodeling in older (5575) postmenopausal white and black women. J Bone Miner Res. 1994:9:1267-1276.

27. Finkelstein JS, Sowers M, Greendale GA, et al. Ethnic variation in bone turnover in pre- and early perimenopausal women: effects of anthropometric and lifestyle factors. J Clin Endocrinol Metab. 2002;87: 3051-3056.

28. Cauley J, Danielson M, Gregg E, Vogt M, Zmuda $J$, Bauer D. Calcaneal ultrasound attenuation in older African-American and Caucasian-American women. Osteoporos Int. 1997;7:100-104.

29. Cummings SR, Cauley JA, Palermo L, et al; Study of Osteoporotic Fractures Research Group. Racial differences in hip axis lengths might explain racial differences in rates of hip fracture. Osteoporos Int. 1994; 4:226-229.

30. Nevitt MC, Cummings SR, Kidd S, Black D. Risk factors for recurrent nonsyncopal falls: a prospective study. JAMA. 1989;261:2663-2668.

31. Zmuda JM, Cauley JA, Ferrell RE. Recent progress in understanding the genetic susceptibility to osteoporosis. Genet Epidemiol. 1999;16:356-367.

32. Robbins J, Hirsch C, Cauley J. Associates of bone mineral density in older African Americans. J Natl Med Assoc. 2004;96:1609-1615

33. Parra EJ, Marcini A, Akey J, et al. Estimating African American admixture proportions by use of population-specific alleles. Am J Hum Genet. 1998;63:1839 1851

34. Duan Y, Parfitt A, Seeman E. Vertebral bone mass, size and volumetric density in women with spinal fractures. J Bone Miner Res. 1999;14: 1796-1802.

35. Seeman E, Duan Y, Fong D, Edmonds J. Fracture site-specific deficits in bone size and volumetric density in men with spine or hip fractures. J Bone Miner Res. 2001;16:120-127.

Literature is a method of sudden arrangement of commonplaces. The suddenness makes us forget the commonplace.

—T. E. Hulme (1883-1917) 